See Article page e281.

\section{Commentary: The bat-like conduit - the next superhero to combat gastric malperfusion?}

\author{
Monisha Sudarshan, MD, MPH, and \\ Siva Raja, MD, PhD
}

Esophageal surgeons have distinctive approaches in constructing the gastric conduit yet share the same quest to improve conduit perfusion, minimize anastomotic leaks, and optimize functional outcomes. There are of course some shared principles in conduit preparation that include preservation of the right gastroepiploic artery, atraumatic handling, and avoidance of staple shelves. Beyond these basic tenants, there is little expert consensus on what constitutes the ideal conduit with some constructing narrow conduits, some wider conduits, and few that use the entire nontubularized stomach. Much of the dogma is based on personal surgeon experience.

In this issue of the Journal, Lai and colleagues ${ }^{1}$ report their work investigating perfusion of the gastric conduit in pig models. We applaud their work because it is one of the few contemporary studies exploring gastric perfusion in an animal model. They focused on changes of blood supply of the gastric tube after a gastric wall defect was performed for anastomosis. The first conduit was a narrow $3-\mathrm{cm}$ tube, and the second conduit started at $3 \mathrm{~cm}$ in width but enlarged to $5 \mathrm{~cm}$ at the distal end corresponding to the location of the anastomosis (the authors called it a "batshaped" tube: unclear if the intended reference is to the bat wing vs something akin to a cricket bat). Perfusion was evaluated using blood gas analysis and methylene blue in the gastric wall distal and proximal to the anastomosis in the 2 different conduits. Their results indicated better perfusion in the distal aspects of the bat-shaped conduit.

The group brings up an interesting facet in conduit construction through this in vivo experiment. Some might even

\footnotetext{
From the Department of Thoracic and Cardiovascular Surgery, Heart and Vascular Institute, Cleveland Clinic, Cleveland, Ohio.

Disclosures: Authors have nothing to disclose with regard to commercial support.

Received for publication Nov 24, 2019; revisions received Nov 24, 2019; accepted for publication Nov 25, 2019; available ahead of print Jan 13, 2020.

Address for reprints: Siva Raja, MD, PhD, Heart and Vascular Institute, Cleveland Clinic, 9500 Euclid Ave J4-1, Cleveland, OH 44195 (E-mail: rajas@ccf.org).

J Thorac Cardiovasc Surg 2020;159:e285-6 0022-5223/\$36.00

Copyright (c) 2019 Published by Elsevier Inc. on behalf of The American Association for Thoracic Surgery

https://doi.org/10.1016/j.jtcvs.2019.11.107
}

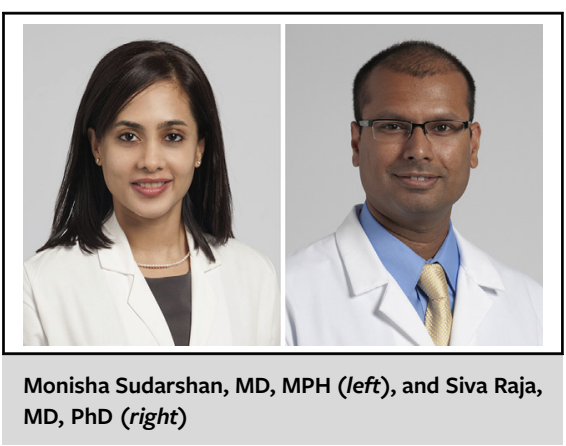

\section{CENTRAL MESSAGE \\ Widening the avascular area near \\ the planned anastomosis may \\ improve local tissue ischemia on \\ the gastric conduit.}

have hypothesized that a wider distal tip would render that area even more ischemic. The authors used $\mathrm{pH}$, base excess, and arteriography for perfusion, but adding the qualitative indocyanine green (ICG) fluorescence imaging may have provided a direct real-life correlation given its frequent use by some surgeons, particularly in tip revision. The experiment used 3 pigs in each group, and understandably there are limitations to conducting large animal studies, but we have to extrapolate the results from such a small study with caution. Furthermore, the application of this bat-shaped conduit would be limited to only a 3-cm conduit, yet a $4-$ or 5-cm conduit is often used by some surgeons. ${ }^{2}$ Moreover, the anastomosis in these models was not actually conducted but rather simulated using a clamp. How accurately a clamp would replicate the surrounding perfusion of a true anastomosis is unclear.

In addition to techniques improving gastric conduit perfusion, novel methods to assess gastric perfusion are emerging to assist the esophageal surgeon in intraoperative decision making and placement of the anastomosis. Use of ICG has been welcomed by many surgeons who have observed a decrease in their anastomotic leak with its guidance $^{3}$; however, its qualitative assessment of perfusion has limited widespread use. New methods in quantitative ICG assessment ${ }^{4}$ and use of a laser-Doppler contact probe ${ }^{5}$ are being explored. However, the actual clinical impact of these new technologies, as in the case of the bat-shaped conduit, remains to be defined. Does making a wider distal end result in fewer anastomotic leaks? Would this increase in perfusion reduce ischemic-associated strictures or fistulas? How can these results be used for end-to-end or side-toside anastomosis? Would a stapled anastomosis still benefit 
from this bat-wing shape? Does preservation of the right gastric artery have an impact on the results? Several questions remain to be answered. However, in this scenario in which the bat-shaped conduit is in combat with the super villain of distal conduit ischemia, which will prevail?

\section{References}

1. Lai Y, Ye X, Wang X, Hu Y. The influence of anastomosis-induced gastric wall defects on the blood supply to the gastric tube. J Thorac Cardiovasc Surg. 2020;159:e281-4.
2. De Leyn P, Coosemans W, Lerut T. Early and late functional results in patients with intrathoracic gastric replacement for oesophagectomy for carcinoma. Eur J Cardiothorac Surg. 1992;6:79-84.

3. Zehetner J, DeMeester SR, Alicuben ET, Oh DS, Lipham JC, Hagen JA, et al. Intraoperative assessment of perfusion of the gastric graft and correlation with anastomotic leaks after esophagectomy. Ann Surg. 2015;262:74-8.

4. Ishige F, Nabeya Y, Hoshino I, Takayama W, Chiba S, Arimitsu H, et al. Quantitative assessment of the blood perfusion of the gastric conduit by indocyanine green imaging. J Surg Res. 2019;234:303-10.

5. Ikeda Y, Niimi M, Kan S, Shatari T, Takami H, Kodaira S. Clinical significance of tissue blood flow during esophagectomy by laser Doppler flowmetry. J Thorac Cardiovasc Surg. 2001;122:1101-6. 